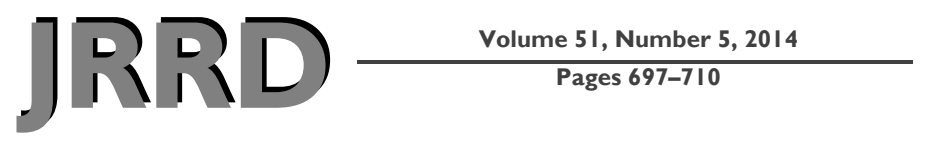

\title{
Glasgow Coma Scale scores, early opioids, and 4-year psychological outcomes among combat amputees
}

\author{
Ted Melcer, PhD; ${ }^{*}$ Jay Walker, BA; $^{1}$ Vibha Bhatnagar, MD; ${ }^{2-3}$ Erin Richard, MPH; ${ }^{2-3}$ Peggy Han, MPH; ${ }^{1}$ \\ V. Franklin Sechriest II, MD; ${ }^{4}$ Martin Lebedda, RN; ${ }^{1}$ Kimberly Quinn, RN; $^{\mathbf{1}}$ Michael Galarneau, MS, NREMT ${ }^{\mathbf{1}}$ \\ ${ }^{1}$ Department of Medical Modeling, Simulation, and Mission Support, Naval Health Research Center, San Diego, CA; \\ ${ }^{2}$ Department of Veterans Affairs San Diego Healthcare System, San Diego, CA; ${ }^{3}$ Department for Family and Preven- \\ tive Medicine, University of California, San Diego, CA; ${ }^{4}$ Naval Medical Center San Diego, San Diego, CA
}

\begin{abstract}
Morphine and fentanyl are frequently used for analgesia after trauma, but there is debate over the advantages and disadvantages of these opioids. Among combat amputees, intravenous (IV) morphine (vs IV fentanyl) after injury was associated with reduced likelihood of posttraumatic stress disorder (PTSD). The previous results were based on military health diagnoses over 2 yr postinjury. The present study followed psychological diagnoses of patients with amputation for $4 \mathrm{yr}$ using military and Department of Veterans Affairs health data. Intheater combat casualty records $(n=145)$ documented Glasgow Coma Scale (GCS) scores and/or morphine, fentanyl, or no opioid treatment within hours of injury. We found that (1) GCS scores were not significantly associated with PTSD; (2) longitudinal modeling using four (yearly) time points showed significantly reduced odds of PTSD for patients treated with morphine (vs fentanyl) across years (adjusted odds ratio $=0.40$; 95\% confidence interval $=0.17-0.94)$; $(3)$ reduced PTSD prevalence for morphine (vs IV fentanyl; morphine $=25 \%$, fentanyl $=59 \%, p<$ 0.05 ) was significant, specifically among patients with traumatic brain injury during the first 2 yr postinjury; and (4) PTSD prevalence, but not other disorders (e.g., mood), increased between year $1(\mathrm{PTSD}=18 \%)$ and years 2 through 4 postinjury (PTSD range $=30 \%-32 \%)$.
\end{abstract}

Key words: combat amputee, fentanyl, Glasgow Coma Scale, Iraq/Afghanistan conflicts, long-term psychological outcomes, loss of consciousness, military and VA health data, morphine, posttraumatic stress disorder, traumatic brain injury.

\section{INTRODUCTION}

Preventing posttraumatic stress disorder (PTSD) is a priority for military healthcare providers because of its adverse effects on health and financial costs [1-9]. For patients with serious combat limb injuries, PTSD can complicate and prolong rehabilitation [8]. PTSD is associated with more sick call visits, missed workdays, increased somatic symptoms [3], poor quality of life outcomes [5], and healthcare costs over $\$ 1$ billion during the first 2 yr after combat injury [7,9]. Although amputations are among the most serious battle injuries, combat amputees injured in the Iraq and Afghanistan wars had reduced likelihood of PTSD compared with limb salvage patients

Abbreviations: $\mathrm{CI}=$ confidence interval; EMED $=$ Expeditionary Medical Encounter Database; GCS = Glasgow Coma Scale; ICD-9-CM = International Classification of Diseases, 9th Revision, Clinical Modification; IRB = institutional review board; ISS = Injury Severity Score; IV = intravenous; NHRC = Naval Health Research Center; OR = odds ratio; PKI = publickey infrastructure; PTSD = posttraumatic stress disorder; $\mathrm{TBI}=$ traumatic brain injury; VA = Department of Veterans Affairs; VHA = Veterans Health Administration.

*Address all correspondence to Ted Melcer, PhD; Naval Health Research Center, 140 Sylvester Rd, San Diego, CA 92106; fax: 619-553-8378. Email: ted.melcer@med.navy.mil http://dx.doi.org/10.1682/JRRD.2013.06.0143 
[6]. Melcer et al. found that early postinjury morphine (vs fentanyl) and loss of consciousness were associated with reduced likelihood of PTSD [10-13], particularly among amputees with a traumatic brain injury (TBI) diagnosis [10]. Some patients with amputation received no opioids (i.e., no morphine or fentanyl) soon after injury, probably to avoid worsening low blood pressure following severe injury [10-14]. The no opioids group (vs fentanyl) also had a relatively low prevalence of PTSD, which may have been related to this group's increased likelihood of postinjury shock and/or loss of consciousness [10].

Most patients with amputation in our previous study (Melcer et al. [10]) received either morphine or fentanyl. Providers debate which of these opioids might be most appropriate for postinjury analgesia [15-17]. Unfortunately, little research has compared the psychological benefits of morphine or fentanyl. Early morphine was associated with reduced likelihood of PTSD among combat casualties injured between 2004 and 2006, but there was little evidence of fentanyl use [18]. More recently, fentanyl has gained support as an alternative to morphine [19]. The onset of morphine-induced analgesia occurs much more slowly than fentanyl [14]. However, morphine produces longer-lasting pain relief than does a similar dose of fentanyl. We hypothesized that morphine reduced PTSD compared with fentanyl because morphine produced more long-lasting pain relief and/or was more effective at blocking memory for trauma than fentanyl $[10,14,18,20]$. Differences between morphine and fentanyl pharmacology and $\mu$ receptor subtypes in the brain [21] may also contribute to differences in the effects of these drugs on memory for trauma and PTSD prevention.

The psychological outcomes in our previous study were limited to diagnoses extracted from military databases [10,22] through 2 yr postinjury [22-23]. Little is known about the long-term psychological outcomes for combat amputees. They typically discharge from military service within the first 2 yr postinjury [6,24-25] and may receive postinjury care from military and/or Department of Veterans Affairs (VA) healthcare systems [26]. Separation from supportive military amputee care [27] presents new social, financial, and occupational challenges of long-term disability [28-31]. These challenges may exacerbate prior symptoms and contribute to new PTSD cases several years after injury [29-30].

The present study followed short- (2 yr) and longterm (4 yr) psychological outcomes using both military and VA health data. It was hypothesized that extended loss of consciousness and intravenous (IV) morphine (vs fentanyl) within hours after injury would be associated with reduced rates of short-term PTSD diagnoses. As in the previous study, we expected this association between IV morphine and PTSD and mood disorder only among patients with TBI. We also expected a general increase in PTSD rates over the long term, based on VA health data showing relatively high rates of PTSD among militaryseparated combat veterans [31-32].

\section{METHODS}

\section{Data Sources}

This collaborative study was approved by the institutional review board (IRB) at the Naval Health Research Center (NHRC) and the IRB at the VA.

\section{In-Theater Injury and Medication Data}

NHRC's Expeditionary Medical Encounter Database (EMED), formerly known as the Navy-Marine Corps Combat Trauma Registry [33], gathers data from NavyMarine Corps levels 1, 2, and 3 military treatment facilities and is supplemented by level 3 data from the Theater Medical Data Store and medical records from levels 4 and 5 facilities treating all military services. The five levels of combat care begin at or near the point of injury (level 1, first aid Army medics/Navy corpsman). Subsequently, patients are evacuated as soon as possible or within hours of injury to level 2 facilities for life-saving resuscitation and hemorrhage control. Within $72 \mathrm{~h}$, patients are transferred to level 3 facilities (e.g., field hospitals) within the combat zone for urgent specialized surgical services. Level 4 facilities serve to provide definitive care outside the combat zone but within the overall theater of operations (e.g., Landstuhl Regional Medical Center in Germany). Level 5 facilities provide medical care within the United States [33].

The EMED uses clinical encounter forms to capture patient data, including time of arrival at treatment facilities, mechanism of injury, Injury Severity Score (ISS) (based on Abbreviated Injury Scale scores assigned by EMED clinicians) [34], and Glasgow Coma Scale (GCS) scores. The EMED encounter forms also capture detailed treatment data, including medications administered during early postinjury resuscitation and trauma care, dosages, and routes of administration, as available. The 
encounter forms are completed by healthcare providers in-theater, either on paper or electronically, and are forwarded to the EMED at NHRC.

\section{Military Health Outcomes}

Combat amputees, their associated anatomical levels of amputations (e.g., single or multiple, upper or lower limb), and subsequent psychological outcomes were identified by searching military health databases [22]. Military health data consist of inpatient and outpatient records, which include International Classification of Diseases, 9th Revision, Clinical Modification (ICD-9CM) diagnostic codes via TRICARE Management Activity. Records were merged from the Armed Forces Health Longitudinal Technology Application, based on inpatient and outpatient encounters by credentialed providers at military treatment facilities and government-reimbursed private clinics. Data were captured from October 2001 through June 2011. The patient identifiers were then encrypted, password protected, and sent electronically to VA investigators using public-key infrastructure (PKI). This allowed patients to be identified and tracked in VA health databases.

\section{Department of Veterans Affairs Health Data}

All patients in the present study first were identified in the military health databases as described. Subsequently, VA investigators at the San Diego VA Healthcare System identified these individuals in the VA National Database [23]. The VA National Database has been used previously in studies on psychological outcomes, including recent veterans of the Iraq and Afghanistan conflicts [31]. VA data, including outpatient diagnoses (ICD-9-CM codes), were extracted from the Corporate Data Warehouse, a national repository of data from Veterans Health Administration (VHA) facility electronic medical record systems (Veterans Health Information Systems and Technology Architecture), and several other VHA clinical and administrative systems. Data extracts were prepared by a VA Informatics and Computing Infrastructure data manager, and downloaded to a secure local VA server using an SAS software interface (SAS Institute Inc; Cary, North Carolina). Data were then merged with deidentifying unique subject identifying numbers supplied by NHRC investigators and stripped of all HIPAA (Health Insurance Portability and Accountability Act of 1996) identifiers. As previously mentioned, the deidentified data were then encrypted, password protected, and sent electronically to
NHRC investigators using PKI. Health data obtained from both military and VA treatment facilities were captured from October 2001 to December 2011.

\section{Patients}

We searched the military health databases to identify U.S. military personnel with major limb amputations (excluding fingers and/or toes alone) who were combat injured in the Afghanistan or Iraq conflicts from 2001 to 2008. Patients who died of wounds or survived with severe brain or spinal injuries leading to paralysis were excluded. Following these exclusions, we identified 857 patients with amputation. This total was consistent with independent counts of all U.S. combat amputees during this period [35]. Of these 857 patients with amputation, only 145 had level 1 or 2 medication records available for analysis. Levels 3 and 4 medication records were obtained for an additional 113 patients (without level 1 or 2 medication records) to increase overall sample size. These 258 patients comprised the sample analyzed for the present study.

At the onset of the Iraq war, there was virtually no capability to capture level 2 casualty records including specific medication data and associated dosages. In that sense, the present sample size is impressive. Early in the Iraq war, NHRC developed a new capability to capture early casualty records for research purposes, namely the EMED. The EMED initially was fielded at Navy-Marine Corps facilities during the time the present study sample of patients with amputation was injured. Of all patients with amputation injured from 2001 to 2008, only about 20 percent were Navy-Marine Corps personnel. Therefore, the EMED captured level 2 casualty records for only about one in five patients with amputation and their associated medication records. We emphasize that medication records are unique and quite valuable because they are collected within hour(s) of combat injury.

\section{Research Design}

This was a retrospective review of existing medical records of U.S. combat amputees injured from 2001 to 2008 in Iraq or Afghanistan. Patient injury data and psychological outcomes were tracked for 48 mo postinjury or until medical records were no longer available in databases. Mechanisms of injury were categorized as blast (e.g., improvised explosive device, rocket-propelled grenade, grenade, land mine, or mortar), gunshot wound, and other (e.g., major blunt trauma or crush injury). ISSs 
were coded by EMED clinicians based on information recorded by forward-deployed healthcare providers [34]. TBI diagnosis was indicated by an ICD-9-CM code within $30 \mathrm{~d}$ of injury in the following range: 800.00801.99 (fractures of the vault or base of the skull), 803.00-804.99 (other unqualified and multiple fractures of the skull), and 850.00-854.10 (intracranial injury, including concussion, contusion, laceration, and hemorrhage) [36]. These TBI diagnostic codes did not distinguish between mild, moderate, or severe TBI.

The GCS scores, medication type, dosage, route of administration, and associated level of care for these data were extracted from in-theater patient encounter forms by trauma research nurses per standard EMED procedures [33]. Patients usually arrive at level 2 care $1-6$ h postinjury, while arrival at level 3 care typically occurs $2-24 \mathrm{~h}$ postinjury. GCS scores of 12 or less, which indicate at least moderate TBI and/or loss of consciousness greater than 30 min [37], at level 2 were used to assess the effect of injury-related alteration or loss of consciousness. Assessments of GCS may have been affected by opioid treatment or other medications. However, 12 percent of both the any morphine group and the fentanyl only group had GCS scores of 12 or less. Further, providers typically consider medication history when assessing GCS and TBI, including repeated GCS assessments to minimize the acute effects of medications on GCS or TBI.

The classifications of medications have been described previously [10]. Briefly, the medications recorded included antibiotics (e.g., cefazolin), general anesthetics (e.g., etomidate), opioid analgesics (i.e., fentanyl or morphine), benzodiazepines (e.g., midazolam), and paralytic and/or muscle relaxants (e.g., succinylcholine, suxamethonium, vecuronium bromide, pancuronium bromide, and/or rocuronium bromide). The U.S. military has established policies for in-theater storage and dispensing of controlled medications, which are carefully logged by physicians [38].

Preinjury psychological diagnoses were analyzed as available in military databases. Postinjury psychological diagnoses were identified in military and VA health databases with ICD-9-CM codes 290-319, excluding 305.10 (tobacco addiction). The primary outcome was a PTSD diagnosis (ICD-9-CM code 309.81) within 24 or 48 mo postinjury. Because previous research has shown that patients with at least two PTSD diagnoses (vs one) in health databases are more likely to have a criterion score on an independent PTSD Checklist-Military version survey of $\geq 50$, we included only patients documented with two or more PTSD diagnoses [39]. The remaining psychological diagnoses were grouped as adjustment, anxiety, mood, substance abuse disorders, and "other" psychological diagnoses. Other psychological diagnoses included postconcussion syndrome, pain, sleep, and unspecified cognitive disorders.

\section{Data Analysis and Study Retention}

The overall study sample consisted of 258 patients with medication data recorded at level 1, 2, 3, or 4 or GCS scores available in the EMED. A subset of 145 patients had at least one level 2 medication (e.g., opioids, paralytics, or antibiotics) recorded with psychological outcomes. Of these 145 patients, 137 also had level 2 GCS scores (8 patients had missing GCS scores). The level 2 medication sample consisted of 115 patients treated with any morphine (morphine alone or combined with fentanyl) or fentanyl alone (3 level 1 patients were included in this subset) and another 30 patients who received no opioids (i.e., no morphine or fentanyl). Prevalence for psychological outcomes was calculated across the first 24 mo for comparison with previous study results [10]. Chi-square or Fisher exact test were used as appropriate to test for significant associations between medications and psychological outcomes. Logistic regressions then were conducted to model relationships between morphine (vs fentanyl) and psychological outcomes, especially PTSD, adjusting for TBI, injury year (2001-2006 vs 2007-2008), and loss of consciousness (as defined by a level 2 GCS score $\leq 12$ ).

Long-term prevalence of PTSD and other psychological disorders was also calculated for consecutive postinjury years 1 through 4 . Longitudinal random intercept models were constructed using the SAS Proc GLIMMIX procedure for Generalized Linear Mixed models (SAS Institute Inc) to evaluate how morphine, fentanyl, TBI, log ISS, age ( $\leq 25$ or $>25 \mathrm{yr}$ ), and years after injury (years 1,2 , 3 , and 4) were associated with the likelihood of having a PTSD diagnosis for patients treated with any morphine or fentanyl only ( $n=115)$. An unstructured covariance structure was selected based on the lowest Akaike information criterion [40]. Finally, longitudinal analyses (The GENMOD procedure, SAS Institute Inc) compared changes in prevalence of psychological disorders for the entire study sample $(N=258)$ across the first 4 yr postinjury. 


\section{RESULTS}

\section{Study Retention}

All patients had at least $3 \mathrm{yr}$ of military and/or VA outcomes data. For the level 2 medication sample (any morphine, fentanyl only, or no opioids), all 145 patients had data through 3 yr postinjury. Patients missing data for year 4 were included in analyses across years 3 and 4. For GCS analyses, 133 of 137 patients (97\%) had outcomes data through 4 yr postinjury. Overall, 231 of 258 patients (88\%) had military and/or VA data for all $4 \mathrm{yr}$ postinjury.

\section{Sample Characteristics}

The overall study sample $(N=258)$ and the subsample of patients with level 2 medication data $(n=145)$ and GCS scores ( $n=137,8$ patients had missing GCS scores) had injury and demographic characteristics that were similar to those of all 857 patients with amputation injured from 2001 to 2008 (Table 1) [10]. (The EMED captured 258 of all 857 patients with amputation, primarily those treated at Navy-Marine Corps facilities.) As described previously [10], the overall study sample and the level 2 medication/GCS sample consisted primarily of young patients ( $70 \% \leq 25$ yr of age) who sustained unilateral (81\%) lower-limb amputations (73\%) following blast injuries (96\%) with moderate to serious ISSs (median $=17$ ). Slightly more than 40 percent of study samples had a TBI diagnosis, which was similar to the overall identified population of patients with amputation $(N=857)$.

\section{Glasgow Coma Scale Scores and Psychological Diagnoses}

Table 2 shows the prevalence of PTSD diagnoses during each of the first $4 \mathrm{yr}$ after combat injury as a function of GCS scores. Clinicians reviewed patient charts for evidence of medications before GCS assessments. Among patients with GCS of 12 or less, 14 of 20 individuals had

Table 1.

Comparison of demographic and injury characteristics for study samples by levels of care versus all amputees injured from 2001 to 2008.

\begin{tabular}{lccc}
\hline \multicolumn{1}{c}{ Demographic/Injury Variable } & $\begin{array}{c}\text { Medication/GCS } \\
\text { Sample Level 2 } \\
\left(\boldsymbol{n}=\mathbf{~ 1 4 5}^{*}\right)\end{array}$ & $\begin{array}{c}\text { Overall Sample } \\
\text { Levels 2-4 } \\
(\boldsymbol{n}=\mathbf{2 5 8})\end{array}$ & $\begin{array}{c}\text { All Amputees } \\
\mathbf{2 0 0 1 - 2 0 0 8} \\
(\boldsymbol{N}=\mathbf{8 5 7})\end{array}$ \\
\hline ISS (mean/median) & $17.9 / 17$ & $18.6 / 16$ & $17.6 / 14$ \\
Age (\% $\leq 25$ yr) & 70 & 63 & 56 \\
Injury Year (\% 2001-2006/\% 2007-2008) & $81 / 19$ & $66 / 34$ & $64 / 36$ \\
Preinjury Psychological Diagnosis (\%) & 6 & 10 & 11 \\
Mechanism of Injury (\% blast) & 96 & 97 & 94 \\
TBI (\%) & 43 & 44 & 38 \\
Location of Amputation (\%) & & & 18 \\
Upper Limb & 20 & 16 & 82 \\
$\quad$ Lower Limb & 80 & 84 & 77 \\
Unilateral Amputation (\%) & 74 & 73 & \\
\hline
\end{tabular}

*Of 145 patients in level 2 medication sample, 137 also had Glasgow Coma Scale (GCS) scores (8 patients had missing GCS scores).

ISS = Injury Severity Score, TBI = traumatic brain injury.

Table 2.

Glasgow Coma Scale (GCS) and posttraumatic stress disorder (PTSD) diagnoses during first 4 yr postinjury.

\begin{tabular}{|c|c|c|c|c|c|c|}
\hline \multirow{2}{*}{ Level 2 GCS } & \multirow{2}{*}{$\begin{array}{c}\text { Total } \\
(n=137)^{*}\end{array}$} & \multirow{2}{*}{$\begin{array}{c}\text { ISS } \\
\text { Mean/Median }\end{array}$} & \multicolumn{4}{|c|}{ PTSD, \% or \% (n) } \\
\hline & & & Year $\mathbf{1}^{\dagger}$ & Year 2 & Year 3 & Year 4 \\
\hline$\overline{13-15}$ & $n=117$ & $17 / 14$ & 19 & 26 & 30 & 32 \\
\hline$\leq 12^{\ddagger}$ & $n=20$ & $23 / 22$ & $10(2)$ & $25(5)$ & $25(5)$ & $25(5)$ \\
\hline
\end{tabular}

${ }^{*} 8$ of 145 patients had missing GCS scores, resulting in final sample size of 137 .

${ }^{\dagger}$ Year 1 difference not statistically significant, $p>0.10$.

${ }^{\ddagger} \mathrm{GCS}$ score $\leq 12$ indicates loss of consciousness of $>30 \mathrm{~min}$.

ISS = Injury Severity Score. 
no evidence of opioids or other narcotics before GCS assessment. Four patients had medication-induced unconsciousness (per intubation procedures) and two others received IV morphine (10 and $20 \mathrm{mg}$ ). During the first year, patients who sustained postinjury loss of consciousness (i.e., GCS $\leq 12$ ) had a trend for lower PTSD prevalence than patients with higher GCS scores, but the finding was not statistically significant. Based on VA data sources, we also noted that PTSD prevalence increased, particularly for patients with lower GCS scores (i.e., GCS $\leq 12$ ). Our prior study found zero out of 20 patients had PTSD diagnoses in military data sources during the first 2 yr postinjury [10]. By comparison, we emphasize that the present study found seven PTSD cases for the same 20 patients when both VA and military data sources were combined. Finally, both GCS groups had similar PTSD rates during years 2 through 4 .

\section{Characteristics of Medications}

The most frequently administered level 2 medications included IV antibiotics and opioid analgesics. The present study focused on opioid analgesics administered at level 2 combat trauma care facilities because these medications, given within hours of injury, have been shown to affect psychological outcomes $[10,18]$. Of the 145 patients in the level 2 medication group, 115 received morphine or fentanyl and 75 percent of these patients had dosage data. Another 30 patients received no opioids but had records of other medications. The median highest dose administered at level 2 was $10 \mathrm{mg}$ for morphine and $100 \mu \mathrm{g}$ for fentanyl. Because the analgesic effect of fentanyl is generally considered 100 times more potent than morphine, the median dosages administered to patients in the present study were approximately equivalent for analgesic effectiveness [16].

\section{Morphine, Fentanyl, and Psychological Diagnoses}

Table 3 shows the level 2 medication sample $(n=145)$ comparing groups who received any morphine, fentanyl only, or no opioids; their associated ISS; and prevalence of patients with TBI, PTSD, or mood diagnoses. Preinjury psychological diagnoses, age (percentage $\leq 25$ yr old), and prevalence of TBI diagnoses did not differ significantly among the three groups. Across TBI status, the no opioids group had significantly higher ISSs than the any morphine or the fentanyl only (opioid-treated) groups (mean ISS: no opioids $=24.2$, any morphine $=16.4$, fentanyl only $=15.7$; $p<0.001$ ).

\section{Short-Term Psychological Outcomes}

During the first 2 yr postinjury, the no opioids group had significantly lower prevalence of PTSD $(20 \%, n=$ $30)$ than the fentanyl group $(53 \%, n=32)$ (chi-square, $p<0.01$ ), but not the morphine group (34\%, $n=83$ ). The no opioids group also had a significantly higher prevalence of provider-documented loss of consciousness (50\%, 15 of 30$)$ than patients who received opioids (11\%, 13 of 115) $(p<0.01)$. Providers advise that patients with severe injuries (i.e., ISS $>20$ ) are not candidates for opioid treatment because they are typically already unconscious with significant blood loss [17]. Therefore, the subsequent analyses focused on comparing patients who received opioid medications, either morphine or fentanyl.

Across TBI status, 34 percent of morphine-treated patients $(n=83)$ had PTSD during the first 2 yr postinjury compared with 53 percent of patients treated with fentanyl only $(n=32)(p<0.05)$. Any morphine (vs fentanyl only)

Table 3.

Postinjury posttraumatic stress disorder (PTSD) and mood diagnoses by early intravenous (IV) morphine or IV fentanyl.

\begin{tabular}{|c|c|c|c|c|c|c|c|}
\hline \multirow{2}{*}{$\begin{array}{c}\text { TBI } \\
\text { Status }\end{array}$} & \multirow{2}{*}{$\begin{array}{c}\text { Level } 2 \\
\text { Medication }\end{array}$} & \multirow{2}{*}{$\begin{array}{c}\text { Sample } \\
\text { Size }\end{array}$} & \multirow{2}{*}{$\begin{array}{l}\text { Median } \\
\text { ISS }\end{array}$} & \multicolumn{2}{|c|}{ PTSD, \% (n) } & \multicolumn{2}{|c|}{ Mood, \% (n) } \\
\hline & & & & Years $1 \& 2$ & Years $3 \& 4$ & Years $1 \& 2$ & Years $3 \& 4$ \\
\hline No TBI & No opioids & 17 & 22 & $12^{\mathbf{a}, \mathbf{b}}(2)$ & $29(5)$ & $18(3)$ & $24(4)$ \\
\hline No TBI & Fentanyl only & 15 & 10 & $47^{a}(7)$ & $40(8)$ & $33(5)$ & $7(7)$ \\
\hline TBI & No opioids & 13 & 24 & $31(4)$ & $31(4)$ & $31(4)$ & $31(4)$ \\
\hline
\end{tabular}

Note: Groups with same superscripts differed significantly (chi-square or Fisher exact test as appropriate, $p<0.05$ ). Across TBI status ( $n=115$ ), any morphine (vs fentanyl) had reduced odds ratio (OR) for PTSD during years 1 and 2, OR = 0.37 (95\% confidence interval $=0.15-0.90$ ), adjusted for age, injury year, and log ISS. ISS = Injury Severity Score, TBI = traumatic brain injury. 
was significantly associated with a reduced prevalence of PTSD during years 1 and 2 (odds ratio [OR] $=0.37$, 95\% confidence interval $[\mathrm{CI}]=0.15-0.90$ ), adjusted for age, injury year, and log ISS. Table 3 also shows the morphine/ fentanyl association with PTSD by TBI status. Among patients with a TBI diagnosis, any morphine (vs fentanyl) had reduced odds of PTSD during years 1 and 2 (OR = 0.23 , 95\% CI $=0.07-0.82$ ), adjusted for age, injury year, and $\log$ ISS. A similar analysis for patients with amputation without a TBI diagnosis did not show a significant association between morphine and PTSD. We conducted separate analyses for psychological diagnoses during the third and fourth years postinjury and found no statistically significant association between the early treatment of patients with IV morphine (vs IV fentanyl) and subsequent development of PTSD or mood diagnoses, regardless of TBI status.

\section{Longitudinal Analyses: Traumatic Brain Injury, Morphine, Fentanyl, and 4-Year Outcomes}

Longitudinal models of PTSD outcomes over $4 \mathrm{yr}$ postinjury included opioid treatment (any morphine vs fentanyl); TBI; and additional covariates, namely preinjury psychological diagnosis, log ISS, and age. There were no significant 3- or 2-way interactions involving the opioid variable using either two time points (i.e., years 1 and 2 vs years 3 and 4 ) or four time points (i.e., years 1, 2, 3, and 4). The longitudinal analysis with four time points (Figure 1) showed a statistically significant effect of opioid treatment (morphine vs fentanyl) on PTSD over time (adjusted OR = 0.40 , 95\% CI $=0.17-0.94$ ). Among patients with TBI, morphine (vs fentanyl) was associated with reduced odds of PTSD, but the trend was not statistically significant $(p=$ 0.06 , adjusted $\mathrm{OR}=0.25,95 \% \mathrm{CI}=0.06-1.04, p=0.06$ ). Models were adjusted for time trend, log ISS, and age.

Table 4 shows rates of anxiety, adjustment disorders, and substance abuse among morphine- and fentanyltreated patients according to TBI status. There were no significant associations between morphine (vs fentanyl only) for any of these psychological outcomes during years 1 and 2 or years 3 and 4 postinjury. Among patients with a TBI diagnosis, the morphine group showed numerically lower but not statistically significant rates of psychological diagnoses, particularly for anxiety diagnoses during the first 2 yr postinjury.

Four-year psychological outcomes. Figure 2 shows the prevalence of psychological disorders during years 1 , 2, 3, and 4 postinjury. Longitudinal analyses evaluated changes in the prevalence of each disorder across $4 \mathrm{yr}$

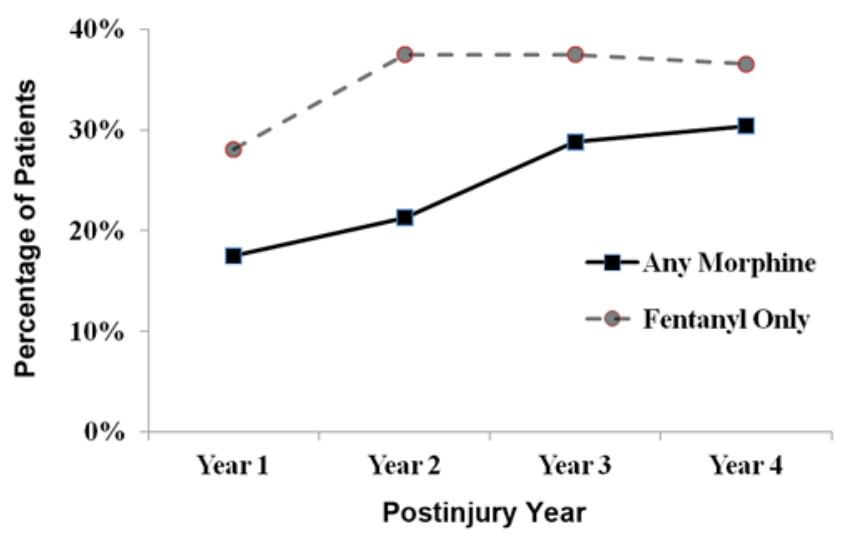

Figure 1.

Prevalence of posttraumatic stress disorder diagnoses among patients treated with any morphine $(n=83)$ or fentanyl only $(n=$ 32) across first 4 yr postinjury.

postinjury (relative to year 1 ). There was a significant increase in PTSD prevalence across the four years $(p<$ 0.001). By comparison to year 1, PTSD increased significantly during years 2,3 , and 4 . By contrast, the prevalence of anxiety, adjustment, and mood disorders decreased significantly across the years (all $p<0.001$, see Figure 1 notes). The prevalence of substance abuse did not change significantly across years. By the fourth year postinjury, PTSD had the highest prevalence of all disorders

Military versus combined military and Department of Veterans Affairs data. Table 5 shows that PTSD prevalence was substantially higher for combined military/VA data than for military data alone. For mood, anxiety, adjustment disorders, and substance abuse disorders, combining military and VA data resulted in much smaller increases than military data alone.

\section{DISCUSSION}

The present study is one of the first to investigate the effect of early postinjury medications on long-term psychological outcomes of combat amputees, based on military and VA health data beginning near the point of injury through the following $4 \mathrm{yr}$ of recovery. The major findings were (1) although patients with extended loss of consciousness had numerically lower PTSD rates during the first year postinjury, the finding was not statistically significant and no further reduction was observed during subsequent years; (2) longitudinal modeling showed 
JRRD, Volume 51, Number 5, 2014

Table 4.

Other postinjury psychological diagnoses by early intravenous (IV) morphine or IV fentanyl.

\begin{tabular}{|c|c|c|c|c|c|c|c|c|}
\hline \multirow{3}{*}{$\begin{array}{c}\text { TBI } \\
\text { Status }\end{array}$} & \multirow{3}{*}{$\begin{array}{c}\text { Level } 2 \\
\text { Medication }\end{array}$} & \multirow{3}{*}{$\begin{array}{c}\text { Sample } \\
\text { Size }\end{array}$} & \multicolumn{6}{|c|}{ Psychological Disorder, \% (n) } \\
\hline & & & \multicolumn{2}{|c|}{ Anxiety } & \multicolumn{2}{|c|}{ Adjustment } & \multicolumn{2}{|c|}{ Substance Abuse } \\
\hline & & & Years $1 \& 2$ & Years $3 \& 4$ & Years $1 \& 2$ & Years $3 \& 4$ & Years $1 \& 2$ & Years $3 \& 4$ \\
\hline$\overline{\text { No TBI }}$ & No opioids & 17 & $18(3)$ & $12(2)$ & $18(3)$ & $24(4)$ & $6(1)$ & $6(1)$ \\
\hline No TBI & Any morphine & 51 & 37 (19) & $20(10)$ & $41(21)$ & $16(8)$ & $16(8)$ & $26(13)$ \\
\hline No TBI & Fentanyl only & 15 & $40(6)$ & $20(3)$ & $27(4)$ & $27(4)$ & $7(1)$ & $13(2)$ \\
\hline TBI & No opioids & 13 & $23(3)$ & $8(1)$ & $31(4)$ & $15(2)$ & $8(1)$ & $31(4)$ \\
\hline TBI & Any morphine & 32 & $25(8)$ & $13(4)$ & $44(14)$ & $16(5)$ & $16(5)$ & $16(5)$ \\
\hline TBI & Fentanyl only & 17 & $41(7)$ & $7(1)$ & $53(9)$ & $18(3)$ & $24(4)$ & $12(2)$ \\
\hline
\end{tabular}

Note: No significant differences among TBI or no TBI medication groups (no opioids, any morphine, fentanyl only) during years 1 and 2 or during years 3 and 4 $(p>0.05)$. For TBI/any morphine group, $n$ was only 31 during years three and four.

IV = intravenous, TBI = traumatic brain injury.

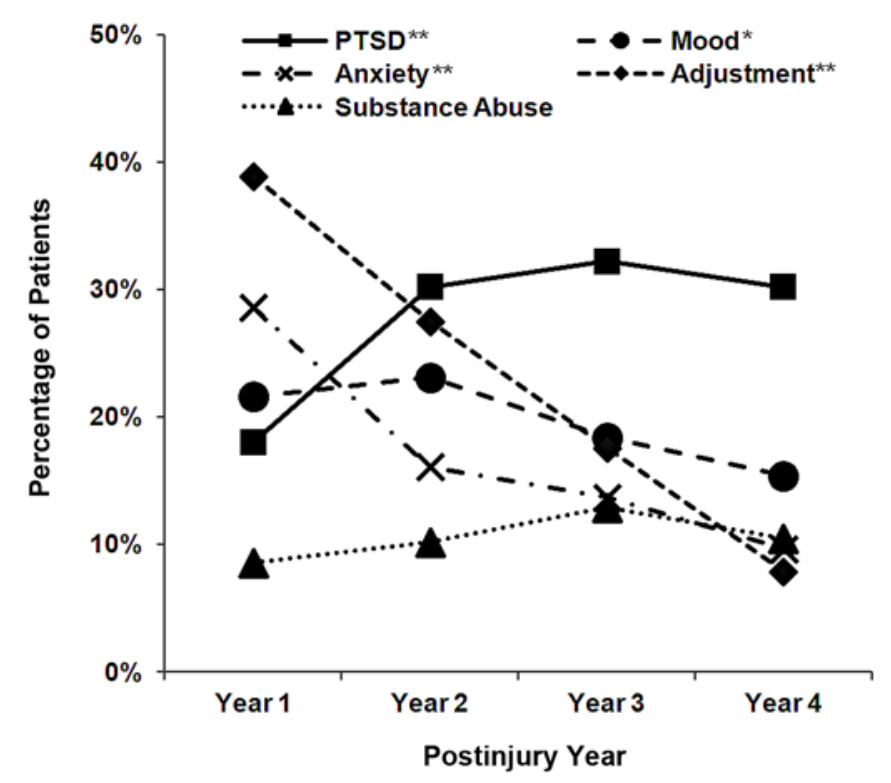

Figure 2.

Prevalence of patients with psychological diagnoses during first 4 yr postinjury. *Year 1 significantly different than year 4 ; Wald $=$ $11.50, p<0.01$ for mood disorder. ${ }^{*}$ Year 1 significantly different than years 2, 3, and 4; Wald $=28.82, p<0.001$ for posttraumatic stress disorder (PTSD); Wald $=34.41, p<0.001$ for anxiety disorder; chi-square Wald $=69.89, p<0.001$ for adjustment disorder.

significantly reduced odds of PTSD for patients treated with morphine (vs fentanyl) across the 4 yr postinjury, after adjusting for postinjury year, age, and injury severity; (3) early treatment with IV morphine (vs IV fentanyl) was significantly associated with reduced PTSD rates, primarily among patients with TBI, during the first 2 yr postinjury; and (4) the association between
IV morphine and reduced rates of PTSD does not appear to extend through the third and fourth years postinjury. A related finding was that PTSD prevalence increased substantially after the first year postinjury, while the prevalence of other psychological decreased across the $4 \mathrm{yr}$.

The finding that loss of consciousness (i.e., GCS $\leq 12$ ) was not associated with reduced PTSD contrasted with findings from our previous study [10]. Both studies showed similar trends for reduced PTSD following loss of consciousness during the first year postinjury. However, this association in the present study was not statistically significant when additional PTSD diagnoses were included from VA health data. Notably, military physicians often refer serious head/spinal injury patients to VA Centers of Excellence rather than less specialized military facilities [32]. This may explain the additional PTSD diagnoses recorded by VA sources, particularly for patients with relatively high GCS scores. Ultimately, because of the small sample sizes and inconsistent findings of previous research [36,41-42], this topic deserves further study.

The present study also found that patients treated with morphine had significantly reduced odds of PTSD than those treated with fentanyl. This finding extended our previous study [10] by integrating the military and VA health data and by longitudinal modeling of the association between early opioids and PTSD outcomes across $4 \mathrm{yr}$ postinjury. The effect of morphine on PTSD appeared strongest during the first 2 yr postinjury among patients with TBI. A previous study found postinjury morphine was associated with reduced likelihood of PTSD, but did not appear to find substantial use of fentanyl for comparison [18]. As in our previous study, we hypothesized that the primary effect of morphine was to prevent PTSD and, 
Table 5.

Prevalence of psychological disorders during first 2 yr postinjury for military versus combined military and Department of Veterans Affairs (VA) health data $(N=258$ combat amputees).

\begin{tabular}{|c|c|c|c|c|c|c|}
\hline \multirow[b]{2}{*}{ Data Source } & \multicolumn{6}{|c|}{ Psychological Disorder } \\
\hline & PTSD & Mood & Anxiety & Adjustment & $\begin{array}{c}\text { Substance } \\
\text { Abuse }\end{array}$ & Other \\
\hline Military Only (\%) & 22.5 & 25.6 & 28.7 & 42.2 & 11.8 & 45.0 \\
\hline Military and VA (\%) & 38.4 & 32.2 & 34.1 & 46.9 & 15.1 & 75.2 \\
\hline
\end{tabular}

secondarily, these patients were also less likely to develop mood disorders [43-44]. There is evidence that both TBI and morphine may interfere with the formation of memory of trauma and later PTSD [18,36]. This may explain why morphine was most effective among patients with TBI.

We emphasize caution in hypothesizing a relationship between morphine, fentanyl, and TBI and PTSD outcomes because of small sample sizes in the present study. There may have been unmeasured patient treatment or injury characteristics that determined whether individuals received morphine or fentanyl. It is possible such characteristics caused the differences in PTSD outcomes observed in the present study. However, our multivariate analyses adjusted for patient characteristics such as age and injury severity and the morphine/fentanyl variable remained a significant predictor of PTSD. Future research should consider in-depth review of individual cases and provider interviews to detail the wide range of patient characteristics that might differ between morphine-treated and fentanyl-treated patients. Ultimately, prospective randomized trials, which may be possible at civilian trauma centers, can provide the strongest test of the effect of early opioids on psychological outcomes.

The primary clinical implication of the present study and our previous results $[10,18]$ is that combat care physicians may consider PTSD prevention as a potential benefit of choosing early IV morphine (alone or combined with IV fentanyl) versus IV fentanyl alone [17-18,20]. IV morphine or morphine combined with fentanyl may interfere with postinjury neurological processes required for memory of combat trauma and thereby protect against later PTSD [18,45]. Alternatively, the present results might be explained by the protective effects of morphine and/or the negative effects of fentanyl on PTSD. As discussed, these opioids have differences in opioid receptor subtypes in the brain and in the duration of their analgesia [14,21], which may explain their different effects on pain, traumatic memory, and PTSD. A previous randomized study showed that postinjury pain was similar between morphine- and fentanyl-treated patients until 40 to 60 min after surgery, and thereafter fentanyl-treated patients reported more pain [17]. In practice, one may question whether medication shortly after a specific combat injury, such as amputation, might be effective in reducing PTSD. Combatants likely experience prior stressful events during deployment (e.g., firefights, witnessing injuries). However, patients who are wounded in combat and those with particularly severe injuries have the highest likelihood of later PTSD [2,4,4647]. Therefore, it appears reasonable to suggest that morphine treatment following a combat injury may reduce the likelihood of later PTSD.

Importantly, a second implication should be drawn from the finding that combat amputees have increased rates of PTSD over the first 4 yr postinjury. Specifically, military and VA providers should use routine healthcare visits (e.g., primary care) as an opportunity for regular and proactive screening for mental health disorders for several years after injury. One explanation is that new postinjury stressors or trauma [28-29] caused new cases of PTSD with delayed onset. Most amputees leave military service within the first year or two after injury [6,24] and typically make substantial and sometimes difficult lifestyle changes as civilians. Alternatively, healthcare utilization or reporting bias may have occurred both very early and also several years later postinjury. Nearly all patients with amputation receive appropriate psychological screening from military providers soon after injury $[6,8]$. However, patients may not have reported PTSD to military providers to avoid stigma or negative effect on their military career [2]. They may also have been diagnosed with related conditions, including other anxiety and mood disorders [6]. Initial VA healthcare evaluations typically follow separation from military service, and patients may have been more likely to report mental health issues to VA providers at this time. These VA diagnoses likely will not be seen by their civilian employer 
and may facilitate VA benefits for appropriate treatment. (However, there is no strong evidence of an association between benefit seeking and PTSD [1].) In general, our finding that combat amputees have increasing prevalence of PTSD over the first 4 yr postinjury supports a sustained and proactive approach by military and VA health professionals to screen for mental health disorders.

Many studies of postinjury psychological outcomes of servicemembers injured in the Iraq and Afghanistan conflicts have studied the first $2 \mathrm{yr}$ of health outcomes using military data sources [4,6,36]. Even during the first $2 \mathrm{yr}$ after injury, we found substantially higher rates of PTSD and "other" psychological diagnoses such as postconcussive syndrome, using both military and VA data sources versus military sources alone $[6,8,27]$. This finding may also reflect compartmentalization of care, whereby some TBI and/or PTSD cases are referred directly to VA centers for postinjury treatment and, thus, not captured/coded within the military system [32]. Researchers following combat-related PTSD and TBI outcomes should consider incorporating both military and VA health data.

The strengths of the present study included access to casualty records in the EMED, which detailed specific patient injuries, early medications, and GCS scores. We also integrated military and VA health data from near point of injury through 48 mo postinjury for more than 90 percent of patients in the study sample. The primary limitation was small sample size. The diagnostic criteria for PTSD overlaps with other psychological disorders (e.g., TBI, mood, and postconcussion syndrome) and, therefore, cases of PTSD might have been misdiagnosed [32]. To minimize this problem, we included PTSD cases only for patients with at least two separate PTSD diagnoses [39].

As described in our previous study, IV morphine and IV fentanyl have the potential for adverse side effects that may negatively affect hemodynamics. Physicians are encouraged to consider the present results along with military guidelines, which emphasize careful evaluation of trauma patient status before administering these medications [14]. Finally, opioids have great potential for addiction, and consequently, providers should exercise caution and appropriate follow-up for patients receiving morphine and/or fentanyl for analgesia [48].

\section{CONCLUSIONS}

The present study found that combat amputees treated with early IV morphine (vs IV fentanyl) had sig- nificantly reduced PTSD and mood diagnoses during the first 2 yr after injury. These results included both military and VA health data. These associations were specific to patients with a TBI diagnosis. In contrast, morphine was not associated with reduced rates of other psychological outcomes (e.g., adjustment, anxiety, and substance abuse disorders). However, the present study found that early IV morphine was not associated with reduced PTSD rates during the third and fourth year postinjury. Finally, we found a substantial increase in the prevalence of PTSD over the first 4 yr postinjury, a result based on combining military and VA health data to more accurately capture these outcomes. Further research should determine the generality of the present findings to nonamputees with serious combat limb injuries.

\section{ACKNOWLEDGMENTS}

\section{Author Contributions:}

Drafted manuscript: T. Melcer. Contributed significantly to drafting "Introduction" and "Discussion" sections of manuscript: V. Franklin Sechriest.

Critically reviewed manuscript: J. Walker, V. Bhatnagar, E. Richard, P. Han, V. Franklin Sechriest, M. Lebedda, M. Galarneau.

Conducted literature review: T. Melcer.

Assisted in analysis: T. Melcer.

Responsible for overall scientific conduct of study, including military institutional review board (IRB) documentation: T. Melcer.

Integrated military medication data and military and VA health outcomes data, preparing all files for analysis: J. Walker.

Oversaw VA data collection and analysis, including IRB documentation for VA healthcare data: V. Bhatnagar.

Worked with national VA health data centers for data extraction and analysis: E. Richard.

Conducted longitudinal modeling of medications and psychological outcomes: E. Richard.

Organized medication data extracted from casualty records: P. Han. Conducted longitudinal analyses of psychological disorders: P. Han. Presented results at Military Health Services Research Symposium, August 2013: P. Han.

Developed overall clinical approach for classification of medications and psychological outcomes: V. Franklin Sechriest.

Assisted in extraction of medication data from casualty records:

K. Quinn.

Reviewed individual casualty records to document postinjury shock and/or loss of consciousness: K. Quinn.

Directly coded and collected specific medication data from casualty records: M. Lebedda.

Developed access to health databases and casualty records containing injury severity scores and early postinjury medication data:

M. Galarneau.

Financial Disclosures: The authors have declared that no competing interests exist. 
Funding/Support: This material was based on work supported by the Navy Bureau of Medicine Wounded Ill and Injured Program (work unit 61108). This work was also supported by the VA.

Additional Contributions: This study, and the manuscript itself, benefited greatly from advice and assistance from the clinicians, epidemiologists, technical writers, database analysts, and programmers working on the Expeditionary Medical Encounter Database project at the Naval Health Research Center, including Carrie Brown, Mary Clouser, Amber Dougherty, Judy Dye, Natella Feinstein, Troy Holbrook, Charles Jackson, Hoa Ly, Andrew MacGregor, and Gerry Pang. We also thank Jason Goff, LT/NC/CRNA, for his insights into opioid use during casualty care. V. Franklin Sechriest II, MD, is now with the Operational Support Health Unit San Diego, Naval Medical Center San Diego.

Institutional Review: The study was approved by the IRBs at the NHRC (IRB 2007.0016) and by the Research and Development Committee of the San Diego VA Medical Center (H130271).

Participant Follow-Up: The authors do not plan to inform participants of the publication of this study because contact information is unavailable.

Disclaimer: The views expressed in this article are those of the authors and do not reflect the official policy or position of the Department of the Navy, Department of Defense, or the U.S. Government. Approved for public release; distribution is unlimited.

\section{REFERENCES}

1. Dohrenwend BP, Turner JB, Turse NA, Adams BG, Koenen KC, Marshall R. The psychological risks of Vietnam for U.S. veterans: A revisit with new data and methods. Science. 2006;313(5789):979-82. [PMID:16917066] http://dx.doi.org/10.1126/science.1128944

2. Hoge CW, Castro CA, Messer SC, McGurk D, Cotting DI, Koffman RL. Combat duty in Iraq and Afghanistan, mental health problems, and barriers to care. N Engl J Med. 2004; 351(1):13-22. [PMID:15229303] http://dx.doi.org/10.1056/NEJMoa040603

3. Hoge CW, Terhakopian A, Castro CA, Messer SC, Engel CC. Association of posttraumatic stress disorder with somatic symptoms, health care visits, and absenteeism among Iraq war veterans. Am J Psychiatry. 2007;164(1): 150-53. [PMID:17202557] http://dx.doi.org/10.1176/appi.ajp.164.1.150

4. MacGregor AJ, Shaffer RA, Dougherty AL, Galarneau MR, Raman R, Baker DG, Lindsay SP, Golomb BA, Corson KS. Psychological correlates of battle and nonbattle injury among Operation Iraqi Freedom veterans. Mil Med. 2009;174(3):224-31. [PMID:19354083] http://dx.doi.org/10.7205/MILMED-D-03-9107

5. Pittman JO, Goldsmith AA, Lemmer JA, Kilmer MT, Baker DG. Post-traumatic stress disorder, depression, and health-related quality of life in OEF/OIF veterans. Qual Life Res. 2012;21(1):99-103. [PMID:21516356] http://dx.doi.org/10.1007/s11136-011-9918-3
6. Melcer T, Sechriest VF, Walker J, Galarneau M. A comparison of health outcomes for combat amputee and limb salvage patients injured in Iraq and Afghanistan wars. J Trauma Acute Care Surg. 2013;75(2 Suppl 2):S247-54. [PMID:23883916] http://dx.doi.org/10.1097/TA.0b013e318299d95e

7. The Congress of the United States, Congressional Budget Office. A CBO Study: The Veterans Administration's treatment of PTSD and traumatic brain injury among recent combat veterans [Internet]. Washington (DC): Congressional Budget Office; 2012 Feb. Available from: http://www.cbo.gov/sites/ default/files/cbofiles/attachments/02-09-PTSD.pdf

8. Wain HJ, Bouterie A, Oleshansky M. Psychiatric intervention for the orthopedically injured. In: Pasquina PF, Cooper RA, editors. Care of the combat amputee. Washington (DC): Borden Institute, Walter Reed Army Medical Center; 2009. p. 265-75.

9. Cesur R, Sabia JJ, Tekin E. The psychological costs of war: military combat and mental health [Internet]. Cambridge (MA): National Bureau of Economic Research; 2011. Available from: http://www.nber.org/papers/w16927

10. Melcer T, Walker J, Sechriest VF 2nd, Lebedda M, Quinn K, Galarneau MR. Glasgow Coma Scores, early opioids, and posttraumatic stress disorder among combat amputees. J Trauma Stress. 2014;27(2):152-59. [PMID:24668780] http://dx.doi.org/10.1002/jts.21909

11. Matis G, Birbilis T. The Glasgow Coma Scale-a brief review. Past, present, future. Acta Neurol Belg. 2008;108(3): 75-89. [PMID:19115670]

12. Teasdale G, Jennett B. Assessment of coma and impaired consciousness. A practical scale. Lancet. 1974;304(7872): 81-84. [PMID:4136544] http://dx.doi.org/10.1016/S0140-6736(74)91639-0

13. Chiu KB, deRoon-Cassini TA, Brasel KJ. Factors identifying risk for psychological distress in the civilian trauma population. Acad Emerg Med. 2011;18(11):1156-60. [PMID:22044521] http://dx.doi.org/10.1111/j.1553-2712.2011.01206.x

14. Fox DJ, Saunders LD, Menk EJ, Middaugh R. Intravenous anesthesia. In: Zajtchuk R, Bellamy RF, Grande CM, editors. Anesthesia and perioperative care of the combat casualty. Washington (DC): Borden Institute, Walter Reed Army Medical Center; 1995. p. 211-32.

15. Black IH, McManus J. Pain management in current combat operations. Prehosp Emerg Care. 2009;13(2):223-27. [PMID:19291561] http://dx.doi.org/10.1080/10903120802290778

16. Kacprowicz RF, Johnson TR, Mosely DS. Fentanyl for pain control in Special Operations. J Spec Ops Med. 2008; 8(1):48-53.

17. Claxton AR, McGuire G, Chung F, Cruise C. Evaluation of morphine versus fentanyl for postoperative analgesia after 
ambulatory surgical procedures. Anesth Analg. 1997;84(3): 509-14. [PMID:9052292]

18. Holbrook TL, Galarneau MR, Dye JL, Quinn K, Dougherty AL. Morphine use after combat injury in Iraq and posttraumatic stress disorder. N Engl J Med. 2010;362(2):110-17. [PMID:20071700]

http://dx.doi.org/10.1056/NEJMoa0903326

19. Wedmore IS, Kotwal RS, McManus JG, Pennardt A, Talbot TS, Fowler M, McGhee L. Safety and efficacy of oral transmucosal fentanyl citrate for prehospital pain control on the battlefield. J Trauma Acute Care Surg. 2012;73(6 Suppl 5):S490-95. [PMID:23192075] http://dx.doi.org/10.1097/TA.0b013e3182754674

20. Bryant RA, Creamer M, O’Donnell M, Silove D, McFarlane AC. A study of the protective function of acute morphine administration on subsequent posttraumatic stress disorder. Biol Psychiatry. 2009;65(5):438-40.

[PMID:19058787]

http://dx.doi.org/10.1016/j.biopsych.2008.10.032

21. Pasternak GW. Preclinical pharmacology and opioid combinations. Pain Med. 2012;13(Suppl 1):S4-11. [PMID:22420604] http://dx.doi.org/10.1111/j.1526-4637.2012.01335.x

22. Gunderson EK, Garland CF, Miller MR, Gorham ED. Career History Archival Medical and Personnel System. Mil Med. 2005;170(2):172-75. [PMID:15782842]

23. Health Services Research \& Development. Corporate data warehouse [Internet]. Washington (DC): Department of Veterans Affairs, Health Services Research and Development Service; 2012 [updated 2014 Mar 28]. Available from: http:// www.hsrd.research.va.gov/for researchers/vinci/cdw.cfm

24. Stinner DJ, Burns TC, Kirk KL, Ficke JR. Return to duty rate of amputee soldiers in the current conflicts in Afghanistan and Iraq. J Trauma. 2010;68(6):1476-79.

[PMID:20068483] http://dx.doi.org/10.1097/TA.0b013e3181bb9a6c

25. Melcer T, Walker GJ, Galarneau M, Belnap B, Konoske P. Midterm health and personnel outcomes of recent combat amputees. Mil Med. 2010;175(3):147-54.

[PMID:20358702]

http://dx.doi.org/10.7205/MILMED-D-09-00120

26. U.S. Department of Veterans Affairs. Health benefits: returning servicemembers (OIF/OEF/OND) [Internet]. Washington (DC): Department of Veterans Affairs [updated 2012 Aug 16; cited 2013 Feb 13]. Available from: http://www.va.gov/ healthbenefits/apply/returning servicemembers.asp

27. Potter BK, Scoville CR. Amputation is not isolated: An overview of the US Army Amputee Patient Care Program and associated amputee injuries. J Am Acad Orthop Surg. 2006;14(10 Spec No.):S188-90. [PMID:17003197]

28. Copeland LA, Zeber JE, Bingham MO, Pugh MJ, Noël PH, Schmacker ER, Lawrence VA. Transition from military to
VHA care: Psychiatric health services for Iraq/Afghanistan combat-wounded. J Affect Disord. 2011;130(1-2):226-30. [PMID:21051088]

http://dx.doi.org/10.1016/j.jad.2010.10.017

29. Horesh D, Solomon Z, Zerach G, Ein-Dor T. Delayed-onset PTSD among war veterans: The role of life events throughout the life cycle. Soc Psychiatry Psychiatr Epidemiol. 2011;46(9):863-70. [PMID:20582726]

http://dx.doi.org/10.1007/s00127-010-0255-6

30. Andrews B, Brewin CR, Philpott R, Stewart L. Delayedonset posttraumatic stress disorder: A systematic review of the evidence. Am J Psychiatry. 2007;164(9):1319-26.

[PMID:17728415]

http://dx.doi.org/10.1176/appi.ajp.2007.06091491

31. Cohen BE, Gima K, Bertenthal D, Kim S, Marmar CR, Seal KH. Mental health diagnoses and utilization of VA non-mental health medical services among returning Iraq and Afghanistan veterans. J Gen Intern Med. 2010;25(1): 18-24. [PMID:19787409] http://dx.doi.org/10.1007/s11606-009-1117-3

32. Lew HL, Pogoda TK, Hsu PT, Cohen S, Amick MM, Baker E, Meterko M, Vanderploeg RD. Impact of the "polytrauma clinical triad" on sleep disturbance in a department of veterans affairs outpatient rehabilitation setting. Am J Phys Med Rehabil. 2010;89(6):437-45. [PMID:20489391] http://dx.doi.org/10.1097/PHM.0b013e3181ddd301

33. Galarneau MR, Hancock WC, Konoske P, Melcer T, Vickers RR, Walker GJ, Zouris JM. The Navy-Marine Corps combat trauma registry. Mil Med. 2006;171(8):691-97. [PMID:16933807]

34. Copes WS, Champion HR, Sacco WJ, Lawnick MM, Keast SL, Bain LW. The injury severity score revisited. J Trauma. 1988;28(1):69-77. [PMID:3123707] http://dx.doi.org/10.1097/00005373-198801000-00010

35. Armed Forces Health Surveillance Center. Deploymentrelated conditions of special surveillance interest. MSMR. 2011;18(9):17-19.

36. MacGregor AJ, Shaffer RA, Dougherty AL, Galarneau MR, Raman R, Baker DG, Lindsay SP, Golomb BA, Corson KS. Prevalence and psychological correlates of traumatic brain injury in operation iraqi freedom. J Head Trauma Rehabil. 2010;25(1):1-8. [PMID:20051901] http://dx.doi.org/10.1097/HTR.0b013e3181c2993d

37. Centers for Disease Control and Prevention. Blast injuries: traumatic brain injuries from explosions [Internet]. Atlanta (GA): Centers for Disease Control and Prevention [updated 2009 Aug 5; cited 2012 Jul 31]. Available from: http:// www.bt.cdc.gov/masscasualties/blastinjury-braininjury.asp

38. Benedek DM, Schneider BJ, Bradley JC. Psychiatric medications for deployment: An update. Mil Med. 2007;172(7): 681-85. [PMID:17691678] 
39. Gravely AA, Cutting A, Nugent S, Grill J, Carlson K, Spoont M. Validity of PTSD diagnoses in VA administrative data: Comparison of VA administrative PTSD diagnoses to self-reported PTSD Checklist scores. J Rehabil Res Dev. 2011;48(1):21-30. [PMID:21328160] http://dx.doi.org/10.1682/JRRD.2009.08.0116

40. Akaike H. A new look at the statistical model identification. IEEE Trans Automat Contr. 1974;19:716-23. http://dx.doi.org/10.1109/TAC.1974.1100705

41. Hoge CW, McGurk D, Thomas JL, Cox AL, Engel CC, Castro CA. Mild traumatic brain injury in U.S. Soldiers returning from Iraq. N Engl J Med. 2008;358(5):453-63. [PMID:18234750] http://dx.doi.org/10.1056/NEJMoa072972

42. Schneiderman AI, Braver ER, Kang HK. Understanding sequelae of injury mechanisms and mild traumatic brain injury incurred during the conflicts in Iraq and Afghanistan: Persistent postconcussive symptoms and posttraumatic stress disorder. Am J Epidemiol. 2008;167(12): 1446-52. [PMID:18424429] http://dx.doi.org/10.1093/aje/kwn068

43. Brown TA, Campbell LA, Lehman CL, Grisham JR, Mancill RB. Current and lifetime comorbidity of the DSM-IV anxiety and mood disorders in a large clinical sample. J Abnorm Psychol. 2001;110(4):585-99. [PMID:11727948] http://dx.doi.org/10.1037/0021-843X.110.4.585

44. Forbes D, Elhai JD, Lockwood E, Creamer M, Frueh BC, Magruder KM. The structure of posttraumatic psychopathology in veterans attending primary care. J Anxiety Disord. 2012;26(1):95-101. [PMID:22036064] http://dx.doi.org/10.1016/j.janxdis.2011.09.004

45. Fletcher S, Creamer M, Forbes D. Preventing post traumatic stress disorder: Are drugs the answer? Aust N Z J Psychiatry. 2010;44(12):1064-71. [PMID:21070102] http://dx.doi.org/10.3109/00048674.2010.509858
46. Koren D, Norman D, Cohen A, Berman J, Klein EM. Increased PTSD risk with combat-related injury: A matched comparison study of injured and uninjured soldiers experiencing the same combat events. Am J Psychiatry. 2005;162(2):276-82. [PMID:15677591] http://dx.doi.org/10.1176/appi.ajp.162.2.276

47. MacGregor AJ, Corson KS, Larson GE, Shaffer RA, Dougherty AL, Galarneau MR, Raman R, Baker DG, Lindsay SP, Golomb BA. Injury-specific predictors of posttraumatic stress disorder. Injury. 2009;40(9):1004-10.

[PMID:19524912] http://dx.doi.org/10.1016/j.injury.2009.04.006

48. Malchow RJ, King KK, Chan BL, Weeks SR, Tsao JW. Pain management among soldiers with amputations. In: Pasquina PF, Cooper RA, editors. Care of the combat amputee. Washington (DC): Borden Institute, Walter Reed Army Medical Center; 2009. p. 229-63.

Submitted for publication June 19, 2013. Accepted in revised form January 15, 2014.

This article and any supplementary material should be cited as follows:

Melcer T, Walker J, Bhatnagar V, Richard E, Han P, Sechriest VF 2nd, Lebedda M, Quinn K, Galarneau M. Glasgow Coma Scale scores, early opioids, and 4-year psychological outcomes among combat amputees. J Rehabil Res Dev. 2014;51(5):697-710.

http://dx.doi.org/10.1682/JRRD.2013.06.0143

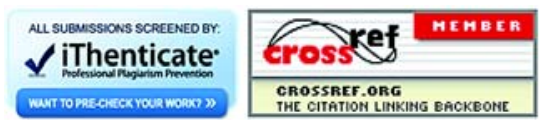


